\title{
SOME TOOLS TO SUPPORT TEACHING PHOTOGRAMMETRY FOR SLOPE STABILITY ASSESSMENT AND MONITORING
}

\author{
M. Scaioni ${ }^{\text {a,b }}$, J. Crippa ${ }^{\text {b,1 }}$, V. Yordanov ${ }^{\text {b }}$, L. Longoni ${ }^{\text {b,c }}$, V.I. Ivanov ${ }^{\text {b }}$, M. Papini ${ }^{\text {b,c }}$ \\ a Dept. of Architecture, Built Environment and Construction Engineering (DABC), Politecnico di Milano, via Ponzio 31, 20133 Italy \\ marco.scaioni@polimi.it \\ b Polo Territoriale di Lecco, Politecnico di Milano, via G. Previati 1/c, 23900 Lecco, Italy \\ (julien.crippa, vasil.yordanov)@mail.polimi.it \\ c Dept. of Civil and Environmental Engineering (DICA), Politecnico di Milano, piazza Leonardo da Vinci 32, 20133 Milano, Italy - \\ (laura.longoni, vladislavivov.ivanov, monica.papini)@polimi.it
}

KEY WORDS: Active Learning, Close-Range Photogrammetry, Geohazards, Landslide Simulation, Low-cost Software, Training

\begin{abstract}
:
This paper describes the use of some tool to help training of photogrammetry for applications in the field of landslide and slope stability assessment and monitoring. These tools have been used in classes of the MSc on Civil Eng. for Risk Mitigation at Politecnico di Milano university, Lecco (Italy). The first tools are hardware facilities. The first one consists of a 'Landslide Simulator,' where shallow landslides may be reproduced at small scale. Simulations are also used here for active-learning purpose. In particular, here the use of digital images to obtain multi-temporal information is presented. The second tool is a 'Rock face 3D Modelling Simulator.' This is used by students to learn how a photogrammetric block should be designed in order to reconstruct rock slopes using Structure-fromMotion photogrammetry. The last to tools are software packages (CloudCompare and LIME) devoted to point cloud analysis (including change detection/ deformation analysis) and advanced visualization, respectively. The combination of these tools together with datasets from either lab and the real field, has been successfully tested to provide efficient training to students in an active-learning fashion.
\end{abstract}

\section{INTRODUCTION}

The application of 3D imaging and scanning techniques for object reconstruction and deformation monitoring may offer today an important support in the assessment, mitigation and forecasting of different types of landslides (Hungr et al., 2014). Among the wide range of sensors and processing methods that can be applied (see Scaioni, 2015), the full maturity of the socalled Structure-from-Motion (SfM) photogrammetry (Westoby et al., 2015; Eltner et al., 2016) provide a useful tool able to deal with many case studies, especially when the size of the investigated area is not wide, and consequently the obtainable photo-scale may be adequate (Luhmann et al, 2014). This holds, for example, in laboratory simulations on scaled-down models, see Scaioni et al. (2013a) and Feng et al. (2016).

As a consequence, SfM photogrammetry (or simply SFM) is a primary tool to learn for people who want to be trained in engineering geology and geohazards related to slope failures. At Lecco Campus of Politecnico di Milano university (Italy), a MSc degree on Civil Engineering for Risk Mitigation (CERM www.cerm.polimi.it) course is active with the purpose of educating students to cope with different types of natural, industrial, chemical, transportation hazards. Multi-disciplinarity is one of the most important key-feature of CERM MSc course, to be implemented through many laboratories where students may learn how to deal with different practical problems related to hazards by using multiple technologies. In the case of landslide and slope stability problems, for instance, students are taught some fundamental background about engineering geology, integrated by some investigating techniques, which may help understand specific case studies. While different types of geophysical methods are used for understanding what is below the surface, 3D imaging and scanning techniques are applied to reconstruct and model the surface. In addition, the latter are used to geolocate where subsurface data have been collected, and to obtain a full surface-subsurface model (Arosio et al., 2009; Longoni et al., 2012). Once data are collected, some methods for assessing the stability of a slope or a rock face are used. These topics are practically taught in an active-learning fashion through some lab activities. These generally involve some of the several case studies that are spread out in the mountain area around the town of Lecco (see, Scaioni et al., 2013b; Longoni et al., 2016). In this context, the use of photogrammetry is particularly efficient for two main reasons: (1) it allows students to be more independent in the analyses because of the relative cheap sensors that are needed and the availability of low-cost, trial and opensource solutions for data processing; (2) in limited-size problems, SfM may provide accurate and detailed 3D digital surface models (DSM) to be use for geological and geotechnical analysis.

In this paper some tools that have been used to support the training of photogrammetry in landslide investigation problems are described. The first consists in a landslide simulation facility ('Landslide Simulator'), that allows to reproduce at smaller scale a slope where shallow landslide may be induced using an artificial rainfall system. Students have the chance to set up a complete simulation experiment as well as to see somehow the soil configuration may control the development of a slope failure. This way, they may physically realize geohazard events that are very difficult to see directly, even better than watching videos. The deployment of a sensor network may be also used to demonstrate somehow different techniques are able to gather observations inherent to the prediction of a slope failure. Among the employed sensors, some digital cameras are installed during simulation experiments to record images for successive photogrammetric reconstruction. In Section 2 some details about the application of photogrammetry for the reconstruction of dynamical 4D models of the experiments is reported.

\footnotetext{
${ }^{1}$ Corresponding author
} 
The second tool is specifically focused to teach students on some how to use SfM and to let them understand which parameters may affect and control the final outputs such as DSMs, orthoimages. In particular, the problem of modelling rock faces to assess their stability and to map the rock fall risk is afforded. While in the field experiments a terrestrial laser scanner is also used, SfM may offer those advantages that have been previously discussed. But before students go in the field to cope with a real case study, a scaled-down model of a rock face is used for training. In Section 3 some examples of the deeper understanding that students may achieve using this tool are illustrated. The rock face scaled-down model also shows the opportunity to work on the basis of the Virtual Geology (Jaboyedoff et al., 2015). Following this approach, a complete, realistic and accurate model of the topographic surface may be used to extract in lab those parameters (for example, dip-dip orientation, joints, etc.) that would be time-consuming, dangerous and sometimes also impossible to directly observe in the field by traditional reconnaissance methods. Thanks to the use of UAV (Unmanned Aerial Vehicles) equipped with an imaging sensor (see Colomina \& Molina, 2014), some non-accessible areas may be reconstructed and analysed. In order to work effectively with Virtual Geology, students should learn how to become familiar with point cloud processing, information extraction and visualization. Training on these tasks is supported by two free software packages: CloudCompare and LIME. Their application will be the subject of Section 4 .

\section{THE 'LANDSLIDE SIMULATOR'}

\subsection{Description of 'Landslide Simulator'}

A 'Landslide Simulator' is a laboratory facility that reproduces on small scale a real slope with its characteristics and destabilizing conditions. With this facility, we may study how external triggering factors (e.g., rainfall or an earthquake) as well as some slope parameters (e.g., inclination) may influence the stability and trigger the landslide. The experimental work on a laboratory model allows for the investigation of various phases which characterize the instability conditions of a shallow landslide: from the onset to the kinematics and post-event study. The main aim of the 'Landslide Simulator' built up at Lecco Campus of Politecnico di Milano university is to investigate the modes of collapse and the factors which may control it: material property, rainfall precipitation intensity, initial moisture content, as well as gradient of the inclined topographic surface. The simulator (Fig. 1) is composed of two adjustable metallic surfaces. The upper part of the flume has dimensions $2 \mathrm{~m} \times 0.8$ $\mathrm{m}$ and could be lifted up to an inclination of $45^{\circ}$. The lateral sides of this flume are made of plexiglass for visual inspection, while the bottom is supplied with a geogrid so as to retain friction between the soil and the structure. Rainfall is simulated with a sprinkler system designed for the purpose. Initially, the material used for landslide simulations is homogeneous fine sand.

\subsection{Hardware implementation of the imaging system}

The 'Landslide Simulator' has been equipped with different types of sensors, including geotechnical, geophysical, fiber-optic instruments. Among these, some cameras have been installed either for visual documentation of the experiments, and for photogrammetric applications (Scaioni et al., 2015a). Here the image acquisition and processing using four GoPro 4 Black $^{\circledR}$ (www.gopro.com) is briefly reviewed. More details can be found in Scaioni et al. (2017).

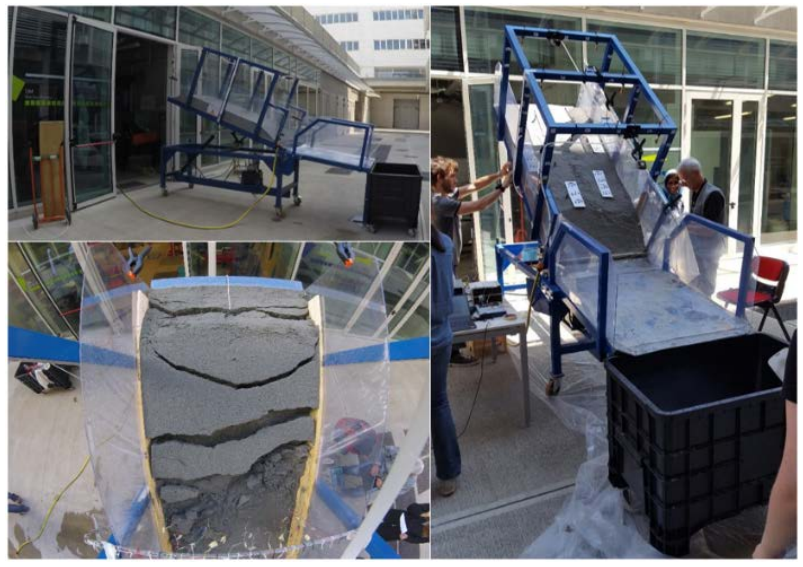

Figure 1. Some photos of the 'Landslide Simulator' set up at Lecco Campus of Politecnico di Milano, Italy.

These sensors are very easy to use and feature some properties that are quite relevant for the application here: they are lightweight, robust, waterproof and with fixed focal length. The time-lapse data acquisition mode allows the recording of an image sequence to be used for further processing. In addition, the GoPro Smart Remote ${ }^{\circledR}$ controller may be used to set up and make synchronous the acquisition of image sequences by multiple cameras. The cost of the adopted camera system is quite small, and this help the sustainability of its application. The position and spatial orientation of each camera has been fixed so that the whole area interested by the expected failure process is captured in at least two sequences (see Fig. 2).

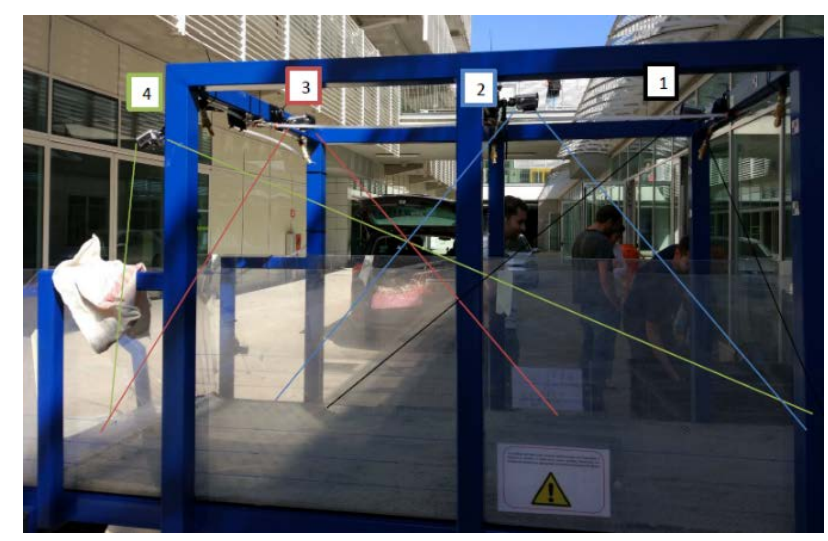

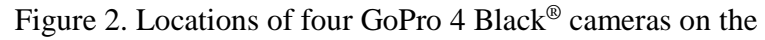
'Landslide Simulator' and the field-of-view of each sensor.

\subsection{Data acquisition and processing}

The up-to-date version of Agisoft Photoscan Professional (APP - www.agisoft.com) has been used for the entire photogrammetric processing workflow. This package is offered in a 30-days free trial-demo version that may be used by students to accomplish their experiments during classes. A cheap release for students is also available for longer usage. 
Since the number of adopted cameras is rather small (four), each sensor has been independently calibrated (Luhmann et al., 2016). Then calibration parameters of each camera are used as input data during SfM and successive dense image matching. A set of 17 markers has been temporarily positioned on the slope to be used as ground control points (GCP) to establish the object reference system of the photogrammetric reconstruction. All GCPs have been measured with a total station, so that their position in a topographic reference system could be determined (i.e., with the $z$ axis aligned along the vertical plumb line). This type of geo-referencing is important since the inclination of the slope has to be known. An initial image data set has been collected before removing markers, to be used for computing the $\mathrm{EO}$ at post-processing stage (Epoch $t_{0}$ ). After this task, markers have been removed and the experiment has been run up to the slope failure (Epochs $t_{1}-t_{n}$ ). In a first stage, after been assigned calibration parameters to each camera, the EO was computed in a free-net fashion using the SfM function implemented in APP ('Image alignment'). In a second stage, six GCP's were manually measured on the images. The BBA including GCP coordinates has yielded the definitive EO of four camera stations. Each block of four synchronous images corresponding to each generic Epoch $t_{i}$ has been then processed in APP to obtain a 'Dense point cloud' for modelling the surface of the slope. The time series of $n$ 3D point clouds may be composed together to create a 4D model. This operation has been preceded by the creation of a triangular mesh to be textured with the image content. These tasks have been automatically done on all the frames of the sequence. A video illustrating the final 4D models may be retrieved online at the following link: goo.gl/1GDyKR. In Figure 3, two reconstructed scenes from a landslide simulation experiment are shown using anaglyphs.

\subsection{Application of Digital Image Correlation (DIC)}

The application of DIC (Chao et al., 2014) has been intended to provide quantitative information on the slope surface displacements and velocities. The implementation distributed by Eberl et al. (2010) has been used, working in Mathworks Matlab ${ }^{\circledR}$ environment. DIC has been applied to the image sequence recorded by GoPro 4 Black $^{\circledR}$ camera No. 3 (see Fig. 2), since this may provide the best view on the area where the largest cracks occurred. To remove the effect of lens distortion, previously computed calibration parameters have been used to output distortion-free images from APP. The DIC code has output displacements evaluated in pixel. Transformation into metric units has been carried out by using the average pixel size. While the 4D models give a view of the slope failure mechanisms, results from DIC provide some qualitative analysis of surface point displacements and velocities. The analysis of this quantity, compared to concurrent observations from other sensors, may allow to understand the physical processes involved with the aim of evaluating the risk of failure.

\section{3. 'ROCK FACE 3D-MODELLING SIMULATOR'}

\subsection{Structure of 'Rock face 3D-Modelling Simulator'}

The 'Rock face 3D Modelling Simulator' consists in a homemade scaled-down model of a rock face, see Figure 4. It is made of a wooden/polystyrene structure drapped with a paper reproducing a real rock texture sold by Crinkle Rock (www.crinklerock.com). The size of the model is $65 \mathrm{~cm} \times 35 \mathrm{~cm}$ $\mathrm{x} 10 \mathrm{~cm}$. The model is also equipped with targets to be used as GCPs and independent check points (IChPs). Using a highly redundant photogrammetric block, the $3 \mathrm{D}$ coordinates of targets have been determined beforehand with a theoretical precision of $0.2 \mathrm{~mm}$. A couple of scale bars in orthogonal directions have been introduced into the scene to fix scaling. On the model surface, it is also possible to position some lichens (or other type of vegetation sold for hobby/decoration purpose) to simulate the presence of bushes overgrown on the rock face surface. Indeed, removing or masking vegetation is a problem when modelling point clouds of such a kind of natural surfaces, see Alba et al. (2011).

The purpose of model is twofold. On one side, to train students on the design of photogrammetric networks useful for reconstruction of a rock face. The same criteria may be transferred to other types of objects as well. Due to the easy accessibility to this test-bed, students may learn by means of a trial-based approach. By repeating the data acquisition using different strategies, students may understand the effect by analysing residuals on IChPs and the properties of the final point clouds, such as density and completeness. For example, by varying the photo scale, by using different image configurations and sensors, they may compare final results. The empirical evaluation of these outputs may give to trainees some concepts about the effects of different parameters and configurations, providing so that a much more solid awareness that the one achievable by theoretical teaching through lectures and handbooks.

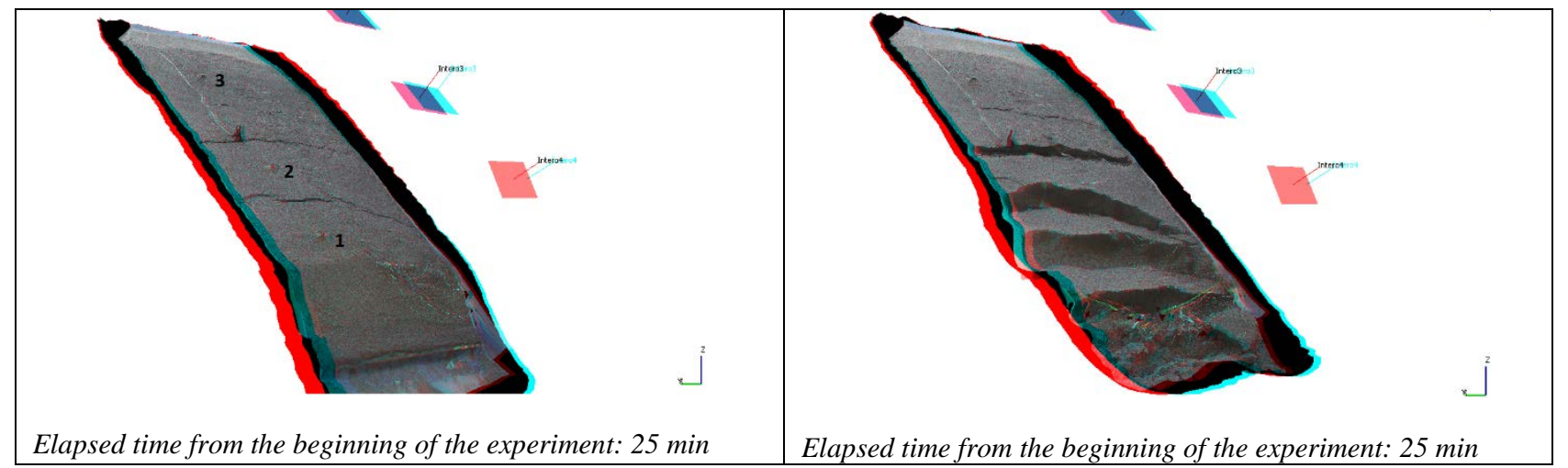

Figure 3. - 3D models corresponding to two key-events during a landslide simulation experiments displayed using anaglyph visualization for 3D stereovision. Numbers in the left figure also show the positions of the three piezometers, while squares represent camera stations (Camera Station 1 is out of field, see Fig. 2). 


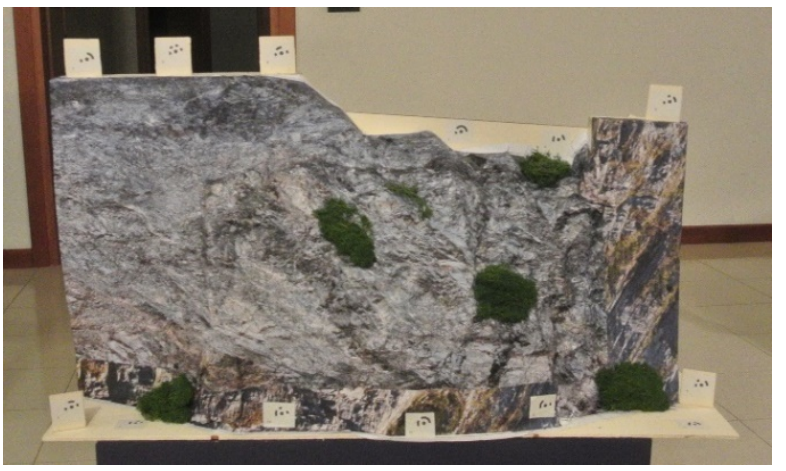

Figure 4. - The 'Rock face 3D Modelling Simulator' with overgrown vegetation.

On the other side, students may have the opportunity to understand and compare different problems related to the processing of the point cloud and the extraction of information. Software tools that will be described in Section 3 have been used to this purpose. For instance, they may understand the complexity of removing vegetation from the reconstructed point cloud, as illustrated in the following subsection.

\subsection{Examples}

The 'Rock face 3D Modelling Simulator' has been used to simulate a case of monitoring/change detection (see Scaioni et al., 2015b), where two photogrammetric surveys have been simulated. The first block has recorded the bare rock, while in the second epoch some vegetations (lichens) where overhang on it as it can be seen in Figure 4. In the current version of this scaled-down model, there is not any possibility to apply changes to the rock. Another model is planned to be implemented to also offer the chance to apply some deformations to a sub-portion of the surface.

Images have been recorded using a Nikon V1 camera, equipped with a zoom lens that has been fixed at the minimum available focal lens ( $c=10 \mathrm{~mm})$. In this example, the camera has been previously calibrated by using a redundant block of convergent images. Of course, independent camera calibration and self-calibration during bundle-block adjustment (BBA) incorporated in SfM are two options that students could try and compare to figure out possible differences in the final outputs. Both photogrammetric blocks have been collected by using a similar configuration in terms of network geometry (see Fig. 5), number of images (21 vs 15), and average photo-scale ( 1:100). Processing has been carried out using SfM workflow implemented in APP up to the generation of two dense point clouds to be compared afterwards.

One of the main purposes of this experiment has been to cope with the problem of removing the overgrown vegetation before computing the departures between both point clouds. Of course, the presence of bushes may influence the deformation analysis. Consequently, the point cloud of the rock face 'with vegetation' (Epoch 2) should be first filtered out to remove those areas covered by bushes. In the case no other data are available (e.g., near-infrared - NIR - images as proposed in Alba et al., 2011), this example may demonstrate how the only analysis of the green component of RGB images is not sufficient to filter out vegetation. Indeed, as it may be seen in Figure 6, a green component is present also in the background rock face, thus using a threshold on the Green band leads also to filter out some parts of the bare rock surface.

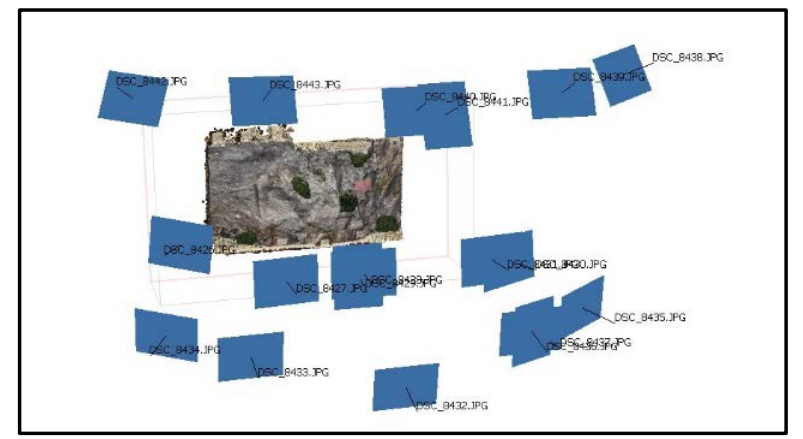

Figure 5. - Photogrammetric network geometry adopted for the reconstruction of the 'Rock face 3D Modelling Simulator.'

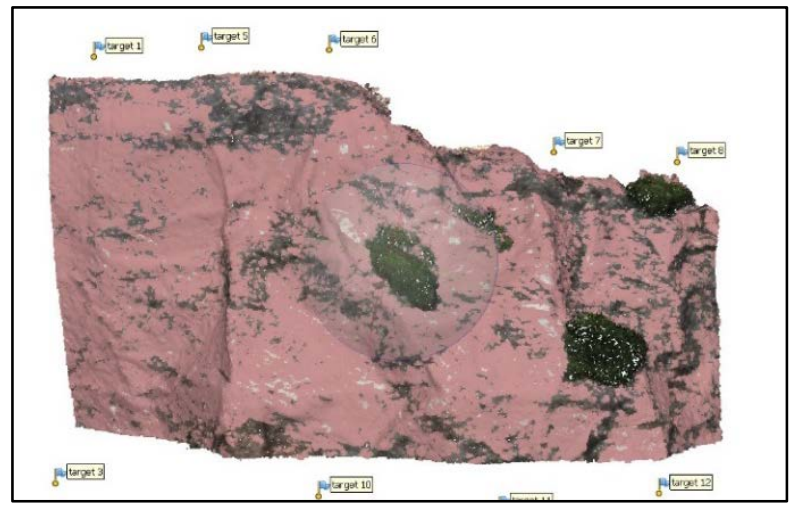

Figure 6. - Result of automatic classification of the 'Rock face 3D Modelling Simulator' point cloud into 'vegetation' (green) and 'bare rock' classes (pink).

A second type of automatic classification method has been tried using a function implemented in APP ver. 1.4.0, which is based on the combination of three geometric criteria: maximum angle between segments connecting close points, maximum off-plane distance, and cell size. Also, this automatic approach has failed because of the similarity between the surface geometry of the bare rock and the outer shape of vegetation spots (Fig. 7). This example also allows to explain the difference between commission (Type I) and omission (Type II) errors.

The results of the automatic classification based on the independent analysis of radiometric (Fig. 6) and geometric (Fig. 7) aspects show how these criteria alone may not provide completely acceptable results. A combination of more criteria or the recourse to additional data is necessary. By using a manual classification, a qualitative evaluation of the classification results can be made. This classification has been 
also adopted for filtering out those regions covered by vegetation to be used in the following change detection/deformation analysis. In this case, the 'Rock face 3D Modelling Simulator' allows to compare different methods for carrying out this task. Here the M3C2 method (Lague et al., 2013) implemented in CloudCompare software package has been applied (see Subsect. 4.1). The advantage of this approach is that the selection of a prevalent direction for surface displacements is not strictly necessary, such as in other techniques (e.g., in Schürch et al., 2011). In addition, the method can keep into consideration also a registration error between both point clouds to compare, and the local roughness. Besides a map of detected displacements (in this case no displacements have been found), other data may be displayed, such as estimated the local noise. These additional information help understand how the algorithm works. Moreover, by mixing the computed displacements and their estimated uncertainty, students may figure out the importance of applying a criterion for discriminating between real displacements and noise (see, e.g., Lindenbergh \& Pietrzyk, 2015; Fei \& Wichmann, 2016).

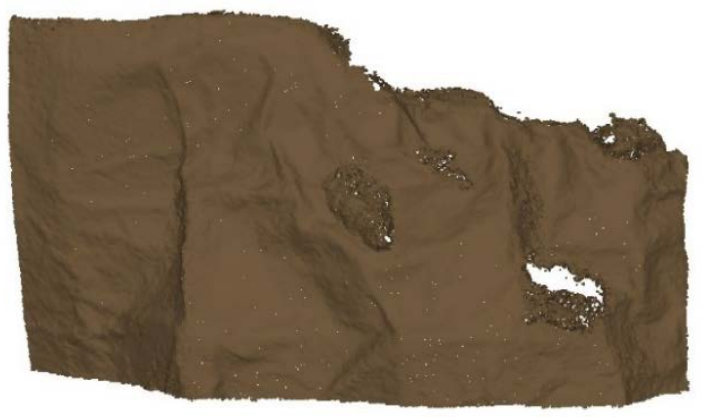

Figure 7. - Result of automatic classification of the 'Rock face 3D Modelling Simulator' point cloud on the basis of geometric properties (brown is 'bare rock' class, while no points have been classified in the 'vegetation' class).

\section{TOOLS FOR POINT CLOUD PROCESSING AND VISUALIZATION}

\subsection{Point cloud analysis: CloudCompare software}

The extraction of information from a point cloud of a rock face may be useful for assessing the stability. In particular, the integration of surface and sub-surface data depicts a more complete view of the stability conditions, see Arosio et al. (2011). Also in this case, experimental data have been used to train students. Two surveys of a real rock face based on photogrammetric and terrestrial laser scanning (TLS) techniques have been carried out to this purpose. In Figure 8, the reconstructed point cloud from SfM and the position of camera stations is shown. More details about data acquisition are omitted in this subsection, since the focus here is on point cloud processing.

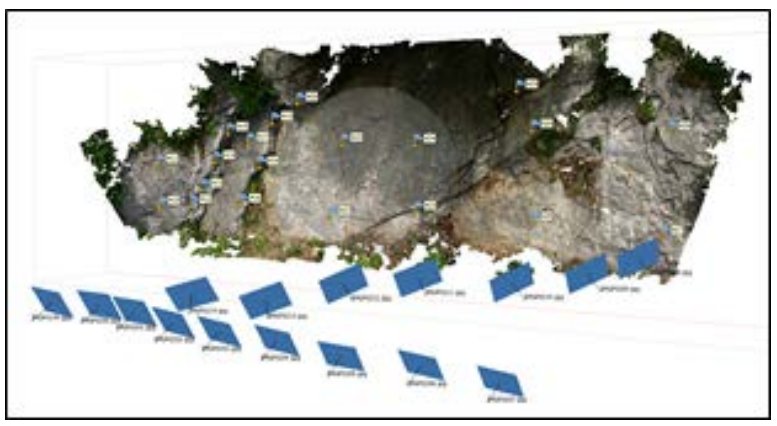

Figure 8. - Point cloud of the reconstructed real rock face based on SfM photogrammetry (blue rectangles are camera stations).

To proceed with the analysis of the rock mass, the point cloud coordinates have been imported in CloudCompare (CC) ver. 2.9.1 (CloudCompare Development Team, 2018). First of all, this environment allows to handle, processing and visualize multiple point clouds in a suitable environment for Virtual Geology. If the rock surface has been correctly represented by the point cloud, its geometric properties may be assessed using CC instead of field reconnaissance, that however is necessary at least for validation. CloudCompare provides a built-in plugin for facet/fracture detection (Dewez et al., 2016). This plugin has two optional processing methods, which may accomplish the segmentation of the point cloud under analysis using two methods: kd-tree and octree (Samet, 2006).

The kd-tree method has been applied to the data set analysed here. Totally 10 planes have been extracted. On the basis of their spatial orientations, these planes have been grouped into two families of discontinuities: Family 1 (9 planes) and Family 2 (1 plane). Using the best fitting plane, the dip and dip direction have been computed. Due to the complexity of the dense cloud, a manual extraction of some planes has been also required in the case of Family 2, resulting in 5 new planes. It can be noticed the fact that in the off-site reports a Family 3 is missing which was previously determined by the on-site survey. None of the automatic and manual plane extraction methods could be applied for the detection of Family 3 because the fractures are very small and after the processing there are not enough points to determine a valid orientation of the joint. These results have been compared to a previous geological survey conducted onsite by using standard surveying tools, such as a geological compass, three families of joints were distinguished. The average values for the dip and dip direction from both types of surveys are reported in Table 9, as well the stereo-plots in Figure10. As it can be seen, results obtained with the automatic method are quite similar to the one obtained from field reconnaissance, except the lack of Family 3.

As already shown in previous sections, students may explore different options and parameters proposed in CC plugin to see how they may affect the analysis. The availability of benchmarking data can be used for checking the results. In addition, point clouds obtained from different acquisition techniques may be compared (TLS vs SfM). 


\begin{tabular}{|c|c|c|c|c|}
\hline \multicolumn{2}{|c|}{ Manual geological survey } & \multicolumn{2}{c|}{$\begin{array}{c}\text { Automatic } \\
\text { extraction }\end{array}$} \\
\hline Family & $\begin{array}{c}\text { Avg. Dip } \\
\left({ }^{\circ}\right)\end{array}$ & $\begin{array}{c}\text { Avg. Dip } \\
\text { Dir. }\left({ }^{\circ}\right)\end{array}$ & $\begin{array}{c}\text { Avg. Dip } \\
\left({ }^{\circ}\right)\end{array}$ & $\begin{array}{c}\text { Avg. Dip } \\
\text { Dir. }\left(^{\circ}\right)\end{array}$ \\
\hline 1 & 56 & 217.5 & 56 & 218 \\
\hline 2 & 30 & 25 & 27 & 2 \\
\hline 3 & 73 & 118.3 & - & - \\
\hline
\end{tabular}

Table 9. - Comparison of parameters of the extracted families of planes as found using the manual and automatic approaches.

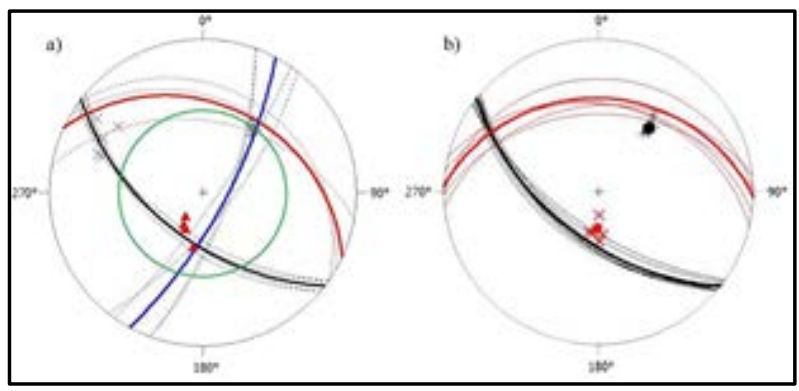

Figure 10. - Stereo-plot from on-site geological survey (a) and from automatic analysis in CC (b). Family 1 is represented by black lines, Family 2 by red lines, and Family 3 by blue lines.

A point cloud has been recorded using a phase-shift TLS Faro CAM2 Focus3D. This instrument is operating in a short range from $0.6 \mathrm{~m}$ to $130 \mathrm{~m}$, with a range accuracy up to $\pm 2 \mathrm{~mm}$. Considering the topography of the surveyed area, one single scan could not capture all the differences and discontinuities of the surface, in consequence two scans with different viewpoints were carried out. They had to be aligned in order to create one dense point cloud. The alignment was performed using five GCPs per each scan, represented by targets positioned on the surface and previously geo-referenced using a total station.

In Figure 11a, the surface comparison between point clouds from TLS and SfM are shown. Since departures below $10 \mathrm{~mm}$ have been retained as non-significant for the extraction of planes and discontinuities, all those points where differences are larger than $10 \mathrm{~mm}$ have been coloured in grey. It is worth mentioning the fact that more than $90 \%$ of the points are below the threshold. This result is very satisfying for a low-cost data acquisition method compared to laser scanning. An additional test has concerned the comparison between two methods for camera calibration: (1) self-calibration within BBA to compute camera EO parameters, and (2) independent calibration. Point clouds obtained from SfM using different calibration sets (1 and 2) have been compared to TLS point cloud. Results are shown in Figure 11a and 11b. It can be noticed that the self-calibration (1) resulted in a better correspondence with the TLS point cloud.

\subsection{Point cloud visualization: LIME software}

LIME software has been developed by Virtual Outcrop Group (Bergen). Currently ver. 1.0 is released under a 180-days free evaluation license. LIME is a 3D viewer of models derived by laser scanning or photogrammetry. The prime purpose is for visualization and interpretation of geological surveys. The imported model can be combined with multiple data sources, while results from the analyses may be used for texturing the 3D model. For example, in Figure 11c the rock face point cloud has been textured with the results of classification into planar families described in Subsection 4.1. The software also allows adding various layers which can benefit to future analyses. For example, with correctly geo-referenced model, one can overlay layers containing the dip, dip direction or strike of the model's plane, which can help for a preliminary analysis (Fig. 11d). Moreover, for more precise measurements LIME software contains some tools, to manually extract different types of information.

\section{CONCLUSIONS}

This paper presented some tools aimed at supporting the teaching of photogrammetry and point cloud processing techniques in landslide and slope stability assessment and monitoring. Examples and results are reported from real experiences carried out by students at CERM MSc degree at Politecnico di Milano university, Lecco (Italy). The reported tools and examples show how this active learning methodology is prone to give to students a major understanding of basic concepts, using an active learning approach.

Of course, new low-cost sensors (for example, gaming 3D sensors, see Pagliari et al., 2015) software packages (e.g., PhoX - Luhmann, 2018) and data sets (Rutzinger et al., 2016) will be developed in the future, also in cooperation with other initiatives (Scaioni et al., 2016). In particular, under the '2018 ISPRS Educational and Capacity Building Initiative,' a project for sharing data sets within a Dissemination Internet Platform has been funded.

\section{Acknowledgements}

First of all, acknowledgements are due to all people who, at different degree, have been involved in the experiments described: Prof. Monica Papini, Dr Diego Arosio, Davide Brambilla, Matteo Canvi, Tarcisio Fazzini, and Vladislav I. Ivanov. We are thankful to Fondazione Cariplo (grant No. 2016-0785) for partial support of this research. Acknowledgements also go to Agisoft company for distributing 30-days free licences of software Photoscan ${ }^{\circledR}$; to Dr C. Eberl, Dr R. Thompson, Dr D. Gianola, and Dr S. Bundschuh for delivering the code for DIC processing; to the CloudCompare Developer Team; to the Virtual Outcrop Group (Bergen) that developed LIME software.

\section{REFERENCES}

Alba M., Barazzetti L., and M. Scaioni, 2011. Filtering vegetation from terrestrial point clouds with low-cost near infrared cameras. Ital J Remote Sens, 43(2): 55-75, doi: 10.5721/ItJRS20114325.

Arosio D., Longoni, L., Papini, M., Scaioni, M., Zanzi, L., and M.I. Alba, 2009. Towards rockfall forecasting through observing deformations and listening to microseismic emissions. Nat Haz Earth Syst Sci, 9(4): 1119-1131. 


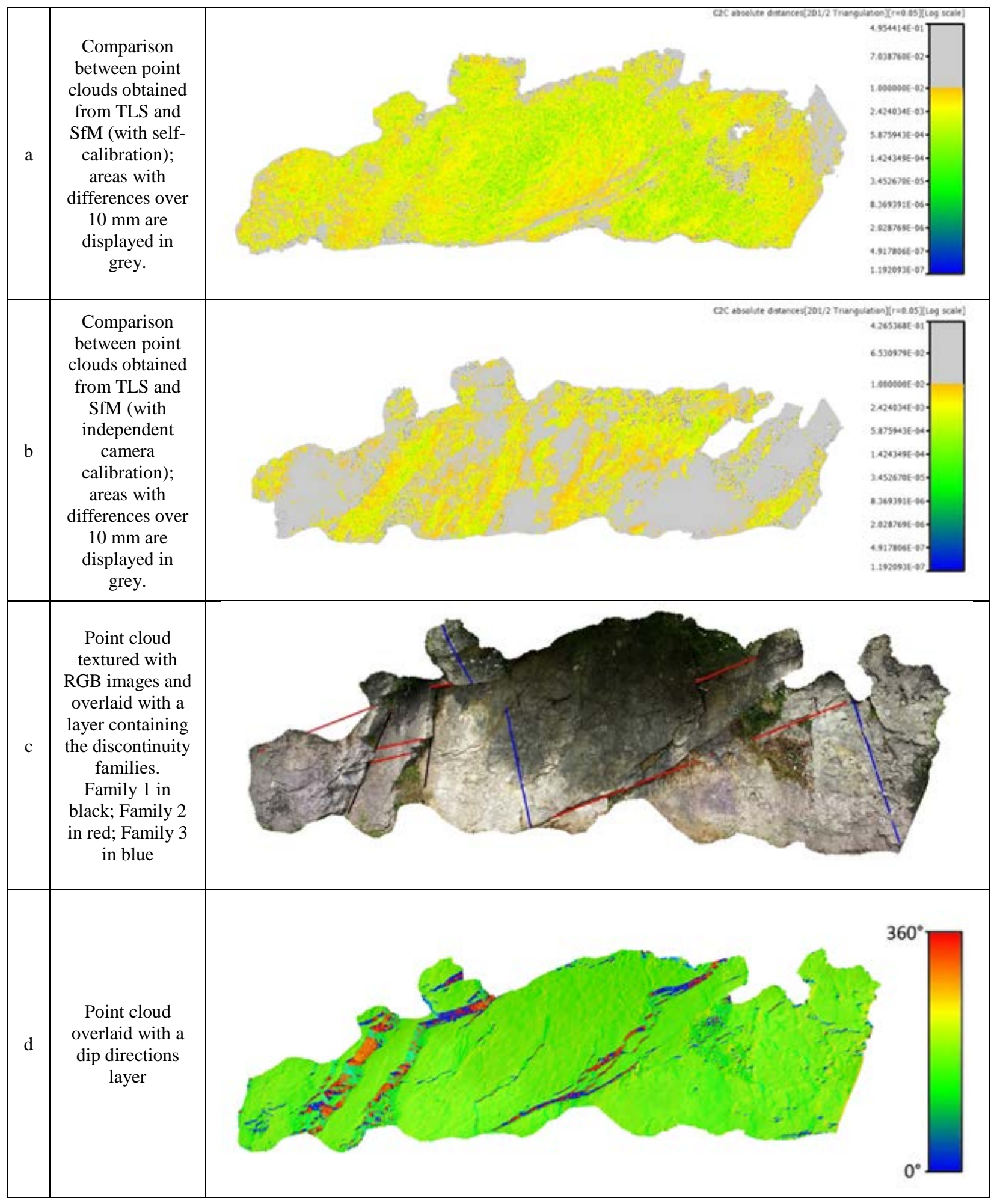

Figure 11. - Results obtained from the analysis of point clouds of a real rock face by using CloudCompare and LIME software packages. 
Chao, H., Gu, Y., and M. Napolitano, 2014. A Survey of Optical Flow Techniques for Robotics Navigation Applications. J Intell Rob Syst, 73(1-4): 361-372.

CloudCompare Development Team 2018. CloudCompare GPL software (ver. 2.9.1). Available online from www.cloudcompare.org (last access on 12/02/2018).

Colomina, I. and P. Molina, 2014. Unmanned aerial systems for photogrammetry and remote sensing: A review. ISPRS $J$ Photogramm Remote Sens, 92: 79-97.

Dewez, T.J.B., Girardeau-Montaut, D., Allanic, C., and J. Rohmer, 2016. Facets: a CloudCompare plugin to extract geological planes from unstructured 3D point clouds. Int Arch Photogramm Remote Sens Spatial Inf Sci, XLI-B5: 799-804, doi: 10.5194/isprs-archives-XLI-B5-799-2016,

Eberl, C., Thompson, R., Gianola, D., and S. Bundschuh, 2010. Digital Image Correlation and Tracking. Available online at https://it.mathworks.com/matlabcentral/ fileexchange/12413-digital-image-correlation-and-tracking (last access on 12/02/ 2018).

Eltner, A., Kaiser, A., Castillo, C., Rock, G., Neugirg, F. and A. Abellán, 2016. Image-based surface reconstruction in geomorphometry - merits, limits and developments. Earth Surf Dyn, 4, 359-389, doi: 10.5194/esurf-4-359-2016, 2016.

Fey, C., and V. Wichmann, 2016. Long-range terrestrial laser scanning for geomorphological change detection in alpine terrain - handling uncertainties. Earth Surf Proc Land, 42(5): 789-802.

Feng, T., Mi, H., Scaioni, M., Qiao, G., Lu, P., Wang, W., Tong, X., and R. Li, 2016. Measurement of Surface Changes in a Scaled-Down Landslide Model Using HighSpeed Stereo Image Sequences. Photogramm Eng Remote Sens, 82(7): 547-557, doi: 10.14358/PERS.82.7.547

Hungr, O., Leroueil, S., and L. Picarelli, 2014. The Varnes classification of landslide types, an update. Landslides, vol. 11: 167-194.

Jaboyedoff, M., Derron, M.-H., Buckley, S.J., a n d M.Scaioni, 2015. Editorial: Introduction to Vertical Geology thematic issue. Eur J Remote Sens, 48: 479-487.

Lague, D., Brodu, N., and J. Leroux, 2013. Accurate 3D comparison of complex topography with terrestrial laser scanner: application to the Rangitikei canyon (N-Z). ISPRS $J$ Photogramm Remote Sens, 82: 10-26.

Lindenbergh, R., and P. Pietrzyk, 2015. Change detection and deformation analysis using static and mobile laser scanning.Appl Geomat, 7(2): 65-74.

Longoni, L., Arosio D., Scaioni, M., Papini, M., Zanzi, L., Roncella, R., and D. Brambilla, 2012. Surface and subsurface non-invasive investigations to improve the characterization of a fractured rock mass. J Geophys Eng, 9: 461-472, doi: 10.1088/1742-2132/9/5/461.

Longoni, L., Papini, M., Brambilla, D., Barazzetti, L., Roncoroni, F., Scaioni, M., and V.I. Ivanov, 2016. Monitoring riverbank erosion in mountain catchments using terrestrial laser scanning. Remote Sens, 8(3), paper No. 241, 22 pages, doi: 10.3390/rs8030241.

Luhmann, T., Robson, S., Kyle, S., and J. Böhm, 2014. Close Range Photogrammetry: $3 D$ Imaging Techniques $-2^{\text {nd }}$ Edition. Walter De Gruyter Inc., Berlin, Germany.
Luhmann, T., Fraser, C., and H.-G. Maas, 2016. Sensor modelling and camera calibration for close-range photogrammetry. ISPRS J Photogramm Remote Sens, 115: 37-46.

Luhmann, T., 2018. Phox. Available online from http://iapg.jade-hs.de/phox/index.php?l=en (last access on 12/02/2018).

Pagliari, D., Passoni, D., Pinto, L., 2015. Monitoring of debris flows using the Microsoft Kinect Sensor. Bollettino della SIFET, 1(2015): 45-52 (in Italian).

Rutzinger, M., Höfle, B., Lindenbergh, R., Oude Elberink, S., Pirotti, F., Sailer, R., Scaioni, M., Stötter, J., and D. Wujanz, 2016. Close-range sensing techniques in alpine terrain. ISPRS Ann Photogramm Remote Sens Spatial Inf Sci, III-6: 15-22, doi: 10.5194/isprs-annals-III-6-15-2016.

Samet, H., 2006. Foundations of Multidimensional and Metric Data Structures. Morgan Kaufmann, 1024 pages.

Scaioni, M., 2015. Modern Technologies for Landslide Monitoring and Prediction. Springer Natural Hazards Series, Springer-Verlag Berlin Heidelberg (Germany), pages 249.

Scaioni, M., Lu, P., Feng, T., Chen, W., Wu, H., Tong, X., Wang, W., and R. Li, 2013a. Analysis of spatial sensor network observations during landslide simulation experiments. Eur J Env Civil Eng, 17(9): 802-825.

Scaioni, M., Roncella, R., Alba, M.I., 2013b. Change Detection and Deformation Analysis in Point Clouds: Application to Rock Face Monitoring. Photogramm Eng Remote Sens, 79(5): 441-456.

Scaioni, M., Feng, T., Barazzetti, L., Previtali, M., Lu, P., Giao, Q., Wu, H., Chen, W., Tong, X., Wang, W., and R. $\mathrm{Li}$, 2015a. Some Applications of 2-D and 3-D Photogrammetry during Laboratory Experiments for Hydrogeological Risk Assessment. Geomatics Nat Haz Risk, 6(5-7): 473-496.

Scaioni, M., Feng, T., Barazzetti, L., Previtali, M., and R. Roncella, 2015b. Image-Based Deformation Measurement. Appl Geomat, 7(2): 75-90.

Scaioni, M., and other 18, 2016. The 'Moon Mapping' Project to Promote Cooperation Between Students of Italy and China. Int Arch Photogramm Remote Sens Spatial Inf Sci, XLI(B6): 71-78, doi: 10.5194/isprs-archives-XLI-B6-712016.

Scaioni, M., Crippa, J., Longoni, L., Papini, M., and L. Zanzi, 2017. Image-Based Reconstruction and Analysis of Dynamic Scenes in a Landslide Simulation Facility. ISPRS Ann Photogramm Remote Sens Spatial Inf Sci, 4(5/W1): 63-70.

Schürch, P., Densmore, A.L., Rosser, N.J., Lim, M., and B.W. McArdell, 2011. Detection of surface change in complex topography using terrestrial laser scanning: application to the Illgraben debris-flow channel. Earth Surf Proc Land, 36(14): 1847-1859.

Westoby, M.J., Brasington, J., Glasser, N.F., Hambrey, M.J. and J.M. Reynolds, 2012. Structure-from-Motion' photogrammetry: A low-cost, effective tool for geoscience applications, Geomorphology, 179: 300-314.

Virtual Outcrop Group Bergen, 2018. LIME software (ver. 1.0). Available online from www.virtualoutcrop.com/lime (last access on 10/02/2018). 